\title{
Social work values, the law and the courts
}

\section{Jonathan Dickens, Professor of Social Work, University of East Anglia.}

The relationships between the law, individual values and society's values have long been matters of intense debate for politicians, judges and philosophers. And social workers, although they may well be seen to lack the professional power or social status of those other groups, find themselves firmly in the middle of those debates - or, as it may be better to put it, at the sharp end. Think of the sort of questions that social workers have to address as part of their everyday job. How much support should be offered to parents to help them care for their children, or when should the children be placed in a different family? When should an individual be detained in a hospital or a care home, without their own agreement? How much money should be spent to help an individual remain living in their own home in the way that they choose, when budgets are limited and demand is high? The law provides one framework for thinking about these difficult matters - what is required and what is allowed, what isn't allowed, what legal processes have to be followed. But the legal provisions have to be seen in the context of wider societal values about family life, the role of the state and the powers of the court; and social workers will also have their own personal beliefs about these matters. Furthermore, social workers have to take account of their organisation's priorities, policies and resources; the service user's wishes, in the light of the person's mental capacity and understanding; and their own professional knowledge, skills and values. Holding these different poles together is what makes social work a profoundly intellectual and ethical profession, as well as a practical one (Dickens, 2016).

In this chapter I want to think more about the relationships between the law, the courts and social work, to explore their different roles and the ways that they interact with one another. At times their values and aims coincide and reinforce one another, and other times different functions and approaches come to the fore, bringing tension and conflict. I shall take two particular issues to illustrate the themes: judgement and justice. Both words have powerful resonance for lawyers and social workers, but the meanings and practical implications are complex and at times contradictory. Social workers are required to exercise professional judgement, but one of their core professional values is not to be judgemental; the courts deliver judgements all the time, and sometimes in ways that are highly critical of social workers. What are the underlying issues here, and the implications? And how does social work's approach to justice square with the formal, legal justice of the courts, and what does it mean for social work's relationship with the law?

The law and the courts have come to play dominant roles in social work in the UK, but it is not certain that this always helps the people who use social work services. Their increasing importance 
chimes with other trends and forces that have given social work in England a highly regulatory character (Social Work Task Force, 2009; Munro, 2011). That is to say, it is tightly regulated itself, but also regulatory in its interactions with service users - highly procedural, often focused on rationing services and assessing and managing risk. But the legalistic approach distorts social work in two senses: it is not always a realistic or fair view of what actually happens, and it pushes social work in certain directions that can be unhelpful to workers and, most importantly, to service users. But things do not have to be like that, and there are examples of more collaborative working between social work and the courts that can help to produce better outcomes for service users. Some forms of independent scrutiny and adjudication will always be necessary, but new approaches to review, challenge and learning are likely to be more productive for longer term constructive change. But first, we need to define our terms.

\section{Values and ethics in social work}

For many social workers, their values are at the heart of their professional identity. They are what motivate them in their day to day work, and what makes their profession distinctive (e.g. Bisman, 2004; Barnard et al., 2008). A social worker's values - say, to treat people fairly, to respect people's choices, to avoid being judgemental or blaming, to empower people to live their lives as independently as possible - will be grounded in their personal beliefs, their professional duties and the wider expectations of their society. Studying the reasons why someone might hold any particular value or set of values, how those values link together, how defensible they are, and what their limitations may be, takes us into the realm of ethics - reasoning about values.

There are many different schools of thought about the underlying principles behind social work values. Four principal schools of ethical thinking are Kantianism (duty-based approaches: one must do one's duty, categorically, regardless of the consequences); utilitarianism (one's duty is to do the thing that brings the greatest good for the greatest number); virtue ethics (it's a question of character, one must train oneself to become the sort of person who makes the right decisions for the right reasons); and care ethics (the important thing is to respond to other people in caring ways, not to be tied to inflexible rules). All of these have direct implications for social work, in thinking about why a worker should act in a certain way, what makes something 'the right thing to do'; and (as we shall see later) there may sometimes be tensions between them (Dickens, 2013).

There are other understandings of what social work is really about, or should be about. In particular, in the current context in England, where social work has become so tightly regulated and regulatory, two powerful counter-trends have emerged. Both seek to recover older, traditional strands of social work, and give them a new lease of life. First, there are those who call for a rediscovery of social 
work's radical edge, its social critique and activism. There has been a resurgence of books with the word 'radical' in the title (e.g. Ferguson and Woodward, 2009; Lavalette, 2011; Ferguson and Lavalette, 2013; Turbett, 2014), the launch of a journal called Critical and Radical Social Work, and the creation of the Social Work Action Network, SWAN. Second, there has also been a revival of relationship-based approaches, those arguing that social work best achieves change not through procedural compliance or political action but through skilful (helpful and realistic) inter-personal helping relationships (e.g. Howe, 2008; Ruch et al., 2010; Munro, 2011; Wilson et al., 2011). It is clear that there are significant differences between the two approaches, and they could well give different answers to what is the right thing for a social worker to do in a certain situation; but Payne (2006) has argued that one of social work's distinguishing features is that it tries to reconcile these two strands, to bring about social change through work with individuals.

So, perhaps one should not overplay the distinction, and think of both/and rather than either/or. We shall return to this in the conclusion. Likewise, one should not overplay the distinction between values and ethics. It is not a rigid or consistent boundary, and the word ethics is sometimes used simply as another term for values, rather than as a more considered way of thinking about values. Examples of this are the various national 'codes of ethics' published by different social work associations around the world, insofar as they tend to set out lists of expectations rather than debate the reasons behind them. There is also an international statement of ethical principles for social work, adopted in 2004 by the International Federation of Social Workers and the International Association of Schools of Social Work (IFSW and IASSW, 2004). National codes are compared usefully in Banks (2012), and it is possible to read a selection on the IFSW website (see their 'National Codes of Ethics' webpage).

\section{Social work values in a nutshell}

The British Association of Social Workers, BASW, is the largest professional body for social workers in the United Kingdom, although membership is not compulsory and the large majority of social workers do not belong. In September 2014, total membership in the four countries of the UK was 17,000, the highest in the association's history (BASW, 2014a: 7). Despite the relatively low numbers it has been established since the 1970s and has an influential voice in on-going debates about the role and the future of social work.

BASW first published its code of ethics for social work in 1975. It was revised in 1986, to give greater weight to anti-oppressive values, and again in 2002 , to enhance the human rights dimensions. A further revision was published in January 2012, to take account of more recent understandings of social work and the challenges that social workers face. The latest code is a succinct summary of 
social work values and a good route into thinking about them, but it should not be considered 'the' definitive statement. It has evolved over time and will no doubt be revised again in the future; and as noted above, other countries have their own codes, which may use different language and emphasise different aspects of professional activity.

The BASW code draws closely on the IFSW and IASSW international statement, highlighting three ways that ethical dilemmas can often arise for social workers (BASW, 2012: 6):

- dealing with conflicting interests and competing rights;

- having a role to support and empower people, alongside statutory duties and other obligations that may be coercive and restrict people's freedoms;

- being constrained by limited resources and organisational policies.

The code goes on to describe three key dimensions of social work ethics: human rights, social justice and professional integrity (the international statement uses the term 'professional conduct'). The BASW code gives five bullet points for each of these headings, and then elaborates on each of them with a further paragraph.

Under the heading human rights, the five points are:

- Upholding and promoting human dignity and well-being

- Respecting the right to self-determination

- Promoting the right to participation

- Treating each person as a whole

- Identifying and developing strengths

Social workers are unlikely to disagree with any of these general objectives. The challenge, of course, is putting general objectives into practice, in two senses: first, because for every general principle there is likely to be another that conflicts with it, and second because social workers have to implement them in the complex and uncertain realities of service users' lives and wishes, the worker's own individual and organisational circumstances, and available resources (time, money, services, community and family support).

In terms of conflicting objectives, these are neatly illustrated in the paragraph that expands on the point about self-determination. It reads: 
Social workers should respect, promote and support people's dignity and right to make their own choices and decisions, irrespective of their values and life choices, provided this does not threaten the rights, safety and legitimate interests of others.

(BASW, 2012: 8)

Two very different approaches to ethical reasoning are bolted together in this sentence, without any explanatory comment or recognition of the potential clashes. The first part of the sentence expresses a categorical view about the importance of an individual's rights to choose and decide about their lives, echoing the Kantian tradition; but the second part goes on to qualify this, balancing it against the rights and well-being of others, a more utilitarian approach. So the absolute importance of the service users' rights to choose, 'irrespective of their values and life choices', is restricted by other considerations that take account of wider, longer-term and social consequences.

Under the heading social justice, the five points are:

- Challenging discrimination

- Recognising diversity

- Distributing resources

- Challenging unjust policies and practices

- Working in solidarity

It is notable here that the requirement on social workers is not simply not to discriminate themselves, but to challenge discrimination. And under the bullet point on challenging unjust policies and practices, the paragraph reads:

Social workers have a duty to bring to the attention of their employers, policy makers, politicians and the general public situations where resources are inadequate or where distribution of resources, policies and practice are oppressive, unfair, harmful or illegal.

(BASW, 2012: 9)

This phrase seems to reflect the radical and campaigning vision of social work. In the current political and economic context, with tightly restricted resources, and policies that seem to be particularly harsh towards people are poor, unable to work, or from other countries, one might expect social workers to be raising issues about resource shortages and unfair policies all the time. But it is important to interrogate exactly what this phrase means, what its implications are for social work as a profession, and social workers as individuals. For a start, there are considerable differences 
between drawing matters to the attention of one's employers or to others outside one's agency, possibly including the general public; and there are differences between situations 'where resources are inadequate', and those were practice is 'illegal'. We return to these issues in more detail later in the chapter.

Under the heading professional integrity, the five points are:

- Upholding the values and reputation of the profession

- Being trustworthy

- Maintaining professional boundaries

- Making considered professional judgements

- Being professionally accountable

One of the implications of the professional integrity heading is that it extends to social workers' behaviour outside their work, and covers the sometimes blurred boundaries between personal and professional lives. An individual's conduct in their private life may possibly damage the values and reputation of the profession; and in some cases may even cause direct harm to vulnerable service users. It raises the question, how private is one's private life? The extreme cases will be clearly unacceptable, but many of the issues are likely to be more ambiguous, with uncertain lines between what is tolerable, what is best dealt with through advice and support, and what requires disciplinary action (Doel et al., 2010).

One of the other points in this section concerns 'making considered professional judgements', and the challenge here is that another of social work's well-known core values is to be non-judgemental. The difference, of course, is that judgementalism is based on prejudice, not knowing (or not taking proper account of) the facts and circumstances. Social workers should certainly avoid this, but as part of their professional duties they are clearly called upon to exercise professional judgement. As the explanatory paragraph in the BASW code puts it:

Social workers should make judgements based on balanced and considered reasoning, maintaining awareness of the impact of their own values, prejudices and conflicts of interest on their practice and on other people.

(BASW, 2012: 10)

But as with all these things, it is often easier said than done; and it is intriguing that there is no mention here of national and organisational policies, team structures and supervision, other 
agencies, or resources. It gives the impression that social workers exercise their judgement alone, but in modern social work practice that is not the case. Social work judgement is not simply an individual matter. And when social work comes into contact with the law and the courts, the tensions between non-judgementalism and proper judgement take on added complexities. These are explored further, later in the chapter.

\section{Legislation and courts}

Just as there is an important distinction between values and ethics, but also overlap and sometimes ambiguity between those terms, so there is an important distinction in the law, between legislation and the courts. Legislation refers to Acts of Parliament, and the related regulations ('secondary legislation'). The important thing to appreciate is that these are political creations, not judicial. They are passed by the government of the day, and are intended to help them achieve their political and policy objectives. In that sense, some Acts are more obviously political than others - that is, they are clearly a response to a wave of public opinion or a media-enhanced scandal, and are meant to show that the government is taking things seriously and is going to tackle these problems. Legislation about immigration controls could be seen under this category, or the repeated calls from some Conservative politicians to repeal the Human Rights Act 1998. Other legislation is designed to introduce policy reforms, such as restructuring the NHS, and even if the policy does not work well it is unlikely that anyone will be brought before the courts for failing to implement it properly. Sometimes legislation may be introduced to set a trap for other political parties. An example would arguably be the Child Poverty Act 2010, which was introduced by the Labour government in the runup to the 2010 general election. No politician could be seen to be in favour of children being poor (especially just before an election), so the Act was passed. Subsequently many politicians in the coalition government expressed unhappiness about the way that child poverty was defined in the Act, with income-based targets, saying that it should not just be about money, but about parental and family circumstances such as worklessness, poor educational achievement and poor parenting (e.g. HM Government, 2011). Shortly after the Conservatives won the general election of May 2015, they announced that they would repeal the targets and change the definition.

So, Acts of Parliament are political, and in some cases the courts will not have any part to play in them. And although individuals may sometimes take their case to court to argue that they should be given a certain service, or allowed to do something, the UK courts cannot overturn decisions about public policy and public spending that are properly made by democratically elected politicians. Under the Human Rights Act 1998, they do have the power to declare legislation incompatible with the European Convention on Human Rights, but not to strike it down. A declaration would mean that 
the law is referred back to the government, and it would then be for Parliament to decide whether or not to amend it. Courts may declare that a particular decision or action by a public authority is unlawful through the process of judicial review, or, under the Human Rights Act 1998, they may declare that it contravenes the European Convention. Under both procedures the court may award damages to the person who has been wronged, and refer the matter back to the relevant agency for reconsideration.

So the courts can contribute to the evolution of law and policy, through the way that judges interpret and apply the law. Indeed, even though their formal powers to change the law or government policy are limited, their judgements may well have considerable impact on the way that a policy is put into practice. An example of this occurred in 2013, in relation to the government's policy of promoting adoption as a permanence option for children who have been removed from their families because of abuse or neglect. The New Labour government, and then the coalition government, had both promoted this through legislation, target-setting and funding initiatives. But in three high profile cases that year, Re B (A Child) [2013] UKSC 33; Re G (A Child) [2013] EWCA Civ 965, and Re B-S (Children) [2013] EWCA Civ 1146, the courts expressed strong views against what they saw as poor practice, from local authorities and the courts. The judgements led to a drop off in adoption plans and orders, and considerable disagreement between the government, social work agencies and the courts (National Adoption Leadership Board, 2014; and see Dickens and Masson, 2014). The impact of these particular cases is discussed in more detail in other chapters in this book, so will not be pursued here; the point here is to highlight the way that courts can affect the implementation of national policy even if they do not have the formal powers to overturn it. But the cases also raise an important issue about the language of blame in the courts. It leads us into discussing the theme of judgement in law and social work.

\section{Judgement and judgementalism}

In Re B-S the language used to criticise the local authority, and by extension other local authorities, was particularly strong. They were criticised for submitting material that was too often 'anodyne and inadequate', with the judge, Sir James Munby, insisting that 'this sloppy practice must stop' (paras 39-40). (Sir James Munby is the President of the Family Division, the leading family judge in England and Wales.) There have been other high profile cases were similarly strong language has been used to criticise individual workers and/or particular local authorities. Two notable examples from child care cases in 2015 are Northamptonshire County Council v AS and Others [2015] EWHC 199 and Re A (A Child) [2015] EWFC 11. In highlighting the critical language, it is not my intention to downplay the fact that practice in these cases fell short of the best standards; rather, it is to show the blaming 
culture of the courts and the antagonism towards local authorities. One of the consequences of the high levels of mistrust between the courts and local authorities has been the long delays in care proceedings that have been damaging to the interests of children and families (Family Justice Review, 2011, esp. paras 4.111-4.120).

In the Northamptonshire case, the judge found there had been delays by the local authority in starting care proceedings on a baby boy (referred to as DS), undertaking the necessary assessments, and filing the court statements and reports. The judge concluded that 'neither the social workers, nor the senior managers at Northampton Children's Services Department had DS's welfare best interests at the forefront of their minds. Worse still they did nothing to promote them. Their chaotic approach to this young baby's care and future life was dismal' (para 14). He spoke of the 'egregious failures' and 'appalling conduct' of the local authority (paras 4 and 32), their 'wholesale failure of DS and his family' (para 34), and a 'catalogue of errors, omissions, delays and serial breaches of court orders [that was] truly lamentable' (para 35). It is clear that there were shortcomings, although it is worth noting that the judge acknowledged that the outcome for DS was 'wholly satisfactory' (para 29). The local authority's evidence shows that there were serious staffing difficulties. It is highly questionable whether such language really helps to improve practice, and whether it helps local authorities to recruit and retain skilled social workers.

The Re A case involved Darlington Borough Council and was another matter heard by Sir James Munby. He described it as 'an object lesson in ... how not to embark upon and pursue a care case' (para 7). He was critical of the lack of clear evidence and analysis, describing the local authority's case as 'a tottering edifice built on inadequate foundations' (para 28), and criticising them for being 'too willing to believe the worst of the father' (para 29). The President accepted some of the authority's concerns about the father but held that '... being an inadequate or even a bad role model is not a ground for making care orders, let alone adoption orders' (para 63). In the judgement, the President went through the local authority's assessment of the father, reading out numerous sections from the social workers' statements, reports and case notes, effectively holding them up to ridicule. He was particularly critical of one of the workers, referred to as 'SW1', calling her work 'seriously flawed' (para 97). Although she is not named, the whole experience must have been crushing and humiliating.

The President does go on to say that ultimate responsibility for the failings lies higher up the organisational hierarchy than the social workers: 'Why, to take her as an example, should the hapless SW1 be exposed to public criticism and run the risk of being scapegoated when, as it might be thought, anonymous and unidentified senior management should never have put someone so 
inexperienced in charge of such a demanding case?' (para 103). But plenty of people will know, or be able to work out, the identity of SW1 and the other workers referred to by their job titles rather than their names ('jigsaw identification'). And rather than softening the blow to the social worker, the effect of the comment is really just to spread blame further.

To reiterate, in describing these examples I am not trying to defend poor practice; rather, it is to make a point about the culture of the court. Courts are cauldrons of blame. They allocate responsibility, and hold people to account; and in criminal cases, they can send people to prison. But child care cases are rather different. They are civil rather than criminal law matters, and in theory the focus is on the welfare of the child rather than apportioning blame for what has happened. (There may be separate criminal proceedings.) But in care proceedings, part of the 'threshold criteria' that the court has to consider are whether the harm to the child is attributable to the care given, or likely to be given, not being what it would be reasonable to expect a parent to give him (s. 31 of the Children Act 1989), so there is an element of attribution of responsibility. This does not necessarily entail blame, because for many of the parents involved in care proceedings, their own problems and limitations are such that blame would be inappropriate. But that creates a problem for the courts, because they are designed to give out blame; that is one of their routine functions. So there is a lot of frustrated blame bubbling away; and it has to escape, and land on someone. It can't be the parents, so it is very often the person standing next to them, so to speak - the social worker.

Looking back to the earlier discussion about social work's approach to judgement and judgementalism, we can see some of the overlaps and tensions between the social work and legal approaches. Social workers can face criticism for failing to exercise proper judgement, either being too blaming or not sufficiently robust.

Generally, social workers try to understand behaviour and avoid allocating blame. This is a core social value, in notable contrast to the views of the former Conservative Prime Minister, John Major, whose advice for dealing with youth offending was to 'condemn a little more and understand a little less' (Maclntyre, 1993). Sometimes personal instinct, professional duty and, it should be remembered, the legal responsibility to support parents in bringing up their children, may lead to decisions to leave children in situations which turn out to be harmful (this risk is compounded by poor supervision, heavy workloads and lack of resources). Most social workers try not to be judgemental, but as Brandon et al. (2009: 27) put it, they have to be careful in case 'efforts not to be judgemental become a failure to exercise professional judgement'.

But at times, the frustrations of working with troubled people who may be aggressive, dishonest and uncooperative, can lead social workers into less constructive ways of thinking, in which they lose 
sight of the positives and themselves become blaming (this danger is also compounded by poor supervision, heavy workloads and lack of resources). By the time a child care case gets to court, it is likely that there will have been considerable efforts, perhaps over a period of years, to try to engage the parents and work with them. So it can be a very distressing experience for social workers if the courts are not convinced, and order further assessments or send the child home/refuse to order the removal of the child. In arguing their case strongly, wanting the best for the child, there is a risk that they may come across as judgemental. Social workers have to be, and come across as, 'the epitome of reason' (Dickens, 2005); but it is not always easy to do this, under extreme pressure and criticism. Courts exercise judgement, of course; but the cases we have been discussing give grounds for thinking that they may be rather judgemental in their approach to social workers and local authorities. Why might this be? One reason is that courts inevitably see the hardest cases, the ones where preventive work and alternatives to care have not been successful. It is important not to assume that these represent the majority of cases. The numbers alone suggest this is not so. Although the number of cases entering care proceedings has risen in recent years, it is still considerably less than the number of children who are subject to child protection plans or child in need plans. There were 10,620 care applications in England in the year April 2013 to March 2014, involving just over 18,000 children (Cafcass, 2015). There were about 8,000 children on interim care orders on 31 March 2014 (i.e. on-going care proceedings: DfE, 2014a: Table A2); but there were 397,600 'children in need' on that day, and 48,300 on child protection plans (DfE, 2014b; and see Dickens and Masson, 2014). In most cases, families and children are helped without going to court. Both the cases described above involved the use of 'section 20' accommodation for children. This is a provision in the Children Act 1989 that allows local authorities to provide accommodation for children (i.e. usually foster or residential care, or possibly to support kinship placements) without going to court, if the parent(s) agree (agreement is not necessary if the parents are missing or cannot be found). Most children who enter care, do so under s. 20; most children who remain in care longer term are on care orders (DfE, 2014a: Tables C3, A2), but there is no time limit on s. 20 and it is possible for children to remain accommodated as long as their parents do not withdraw their agreement. There is often a gulf between lawyers' and social workers' views about s. 20 (see Masson et al., 2013: 201). Lawyers tend to mistrust it, thinking that parents' 'agreement' is often obtained under duress, and it is misused to keep children in care without proper scrutiny by the court. Social workers tend to value it for its flexibility and because it is consistent with their professional values - and indeed, legal requirements - to try work in partnership with families and not to take cases to court if possible (e.g. the family support provisions of s. 17 and the 'no order principle' in s. 1(5) of the Children Act 1989). Certainly, 'agreement' should not be abused and 
parents should be fully informed of their rights, but it is proper for social workers to use their powers of reasoning and negotiation to try to reach agreements with parents. And certainly such cases need to be reviewed carefully to ensure that timely action is being taken and they are not allowed to 'drift'; but one should remember that the courts have the luxury of hindsight, and it is all too easy to criticise social workers for delay when they were trying to find constructive, less adversarial ways of working with the family. The court's mistrust of s. 20 should not be allowed to inhibit local authorities from making full use of this provision to support families, trying to work cooperatively with young people and parents (Dickens et al., 2007).

Another reason for the differences of view may be the social class make-up of the judiciary, compared to social workers and indeed to the parents. Courts are theatres of social class. The rituals, the ways of speaking and dressing, the expectations of 'proper', respectful behaviour, the necessary levels of literacy and verbal expression - all of these reflect and enhance the power of the assured middle and upper classes. One's professional and social status is exposed very clearly in the court, in details such as where a person sits or stands, who they speak to, even whether they are allowed speak. The inequalities of educational background, income and social standing are vast. (A survey by the Sutton Trust in 2005 noted that seven per cent of children in England and Wales attend private schools, but three-quarters of their sample of top judges had done so: Sutton Trust, 2005.) These may be compounded by differences of gender and race. Most senior judges are white men; most social workers are women, and there is a much greater racial diversity in the social care workforce (in December 2012, 83 per cent of employees of local authority children's social care departments in England were female. Overall 86 per cent were white British but this varied around the country, and in London, 43 per cent were of Black, Asian or other minority ethnic origin: DfE, 2013: 10-12). This is not to accuse any judge of sex discrimination or racial prejudice, but it is to point out that judges and social workers tend to come from very different worlds. There are risks of misunderstanding and stereotyping on both sides. The danger is if this leads to a breakdown of trust. Courts have to be independent, of course, and have to be satisfied by the evidence and reasoning. 'Trust' is not uncritical acceptance of what is put before one, but is about respect and understanding, appreciating the contribution of the other person, and awareness of the larger context in which they operate.

There is evidence that more cooperative approaches can produce better outcomes for children and parents. For example, the combined efforts of local authorities, Cafcass and the courts in a pilot programme to reduce the duration of care proceedings, led to significant reductions without reports of impaired thoroughness or justice (Beckett et al., 2013; Dickens et al., 2014). Furthermore, there are encouraging messages from the Family Drug and Alcohol Court, which takes a problem-solving 
approach in care proceedings, using the authority of the judge and the skills of a specialist multidisciplinary drug and alcohol team (Harwin et al., 2014). Collaborative ways of working need not undermine necessary independence, but can enhance a thorough and proportionate response.

\section{Formal justice and social justice}

Let us return to the concept of justice, the second theme in this chapter for exploring the relationships between social work, the law and the courts. Judges and the courts are vital parts of the 'justice system', and people speak of the 'criminal justice system', and the 'family justice system'. As the BASW code showed, justice is also a core principle for social workers, but in a wider sense than the formal justice of the courts. Formal justice is still crucial, and social workers are expected to comply with the duties and powers given by the law, administer them in a fair way, respect the court's procedures and orders, adhere to due process, act on sound evidence and clear reasoning, and so on. But on top of this, social workers have a wider understanding and a professional commitment to social justice. The key elements, as summarised in the BASW code, are challenging discrimination, respecting diversity, ensuring the fair distribution of resources, working with others to overcome social exclusion, and, as discussed earlier, 'challenging unjust policies and practices'.

The law and the courts can be ways of doing that too, but sometimes laws can be oppressive, and courts might enforce unjust laws and unjust social arrangements. As described earlier, the courts have limited power to challenge democratically passed legislation, particularly with regard to public spending. An example in March 2015 was the Supreme Court's decision to refuse an application against the government's cap on the amount of welfare benefits that a family can receive. The case is $R$ (on the application of SG and others (previously JS and others)) (Appellants) v Secretary of State for Work and Pensions (Respondent) [2015] UKSC 16.

One of the reasons for the decision (Lord Reed, para 93 of the judgement) was that the case involved 'issues of social and economic policy, with major implications for public expenditure'. He held that such matters are properly decided by democratically elected institutions, and the court should not intervene unless the policy was 'manifestly without reasonable foundation'. Lady Hale spoke out strongly against the policy, highlighting its harsh impact on women and children. She did not consider it a proportionate means of achieving a legitimate aim, and argued that 'It cannot possibly be in the best interests of the children affected by the cap to deprive [their parents] of the means to provide them with adequate food, clothing, warmth and housing, the basic necessities of life' (para 226). But she was in the minority and the appeal was lost. 
One cannot rely on the courts for radical social change. The 'haves' usually come out ahead (Galanter, 1974). That is not to say that the courts cannot defend the interests of individuals in some circumstances, and as noted earlier they can influence the way that law and policy is put into practice (whether for good or ill may be a matter of contention); but social change is primarily a matter of campaigning, awareness raising and political activity, not litigation (Cranston, 2007: 316). Courts may respond to these wider forces, but they do not lead them.

The distinction between formal justice and social justice links with ideas about human rights, where a distinction is often drawn between 'first generation', civil and political rights (e.g. not to be subjected to cruel, inhuman or degrading treatment or punishment; freedom of thought and conscience; right to private and family life; freedom from arbitrary or unlawful arrest or detention), and 'second generation', economic, social and cultural rights (e.g. rights to fair wages; safe and healthy working conditions; an adequate standard of living; the highest attainable standard of physical and mental health). Traditionally, first generation rights have been defended by lawyers in the courts; second generation rights are promoted through the activities of the welfare state and relevant agencies and social professionals. This is another distinction which is useful but not always clear-cut, and should not be over-drawn. Human rights are indivisible, and lawyers can argue for second generation rights, just as social workers and their agencies have to uphold first generation rights (Ife, 2012; Dickens, 2013).

Even so, there is a difference of character between the two sorts of rights. BASW has a human rights policy which makes the point that human rights, as they have been passed into legislation in the UK, often have a narrower meaning than in social work's professional values, where they are linked to wider questions of social justice and equality (BASW, 2015). The question of resources hangs very large over second generation rights. We have already mentioned some of the questions that arise from the requirement that social workers should bring situations 'where resources are inadequate or where distribution of resources, policies and practice are oppressive, unfair, harmful or illegal' to the attention of their 'employers, policy makers, politicians and the general public'. (Note that this requirement is also in the international statement of ethical principles, not only in the BASW code, although the international version does not include 'illegal'.)

There are three dimensions in this requirement: first, bringing issues of resources and perceived unfairness to the attention of employers; second, to the attention of people outside one's agency; and third, what to do about illegal decisions, policies or practice.

BASW has a policy for employers of social workers to establish effective and ethical working environments (BASW, 2013). It is based on the IFSW policy for employers (IFSW, 2012), but inserts 
some additional sections to describe the UK policy, organisational and practice contexts. One of its key points is that:

... the most effective social work takes place in environments which balance respect for professional values and standards with organisational accountabilities. An open environment which encourages learning, critical reflection and challenge, fully involving service users/consumers/clients in these processes, is more likely to result in high quality services, public satisfaction and the avoidance of bad practice ...

(BASW, 2013: 8)

So within agencies, it is important that there is a commitment to high standards, an understanding of social work's professional values alongside proper arrangements for managerial and resource accountability, a culture of openness, and willingness to involve and learn from people who use social work services. It is also important that there are effective workload management policies, a good physical work environment, a commitment to ongoing training and development, good quality social work supervision, and systematic reviews of services and practice (BASW, 2013: 12-13).

For all that, many decisions about resources and policies are made above the level of the social worker's organisation; they may not even come from the two central government departments that lead on children's services and adult social care, the Department for Education and the Department of Health respectively. Decisions about welfare benefit payments, immigration and asylum policy, and NHS or school re-organisations may well have profound implications for people who use social work services. Social workers may have strong views about these matters, and may be active in campaigning about them in their own time, perhaps through membership of a political party. However, it is not straightforward to say how far, or by what means, they should raise matters with 'policy makers, politicians and the general public'.

Most social workers in the UK are employed in statutory agencies, such as local authorities and health trusts (although the largest single employer of social workers in England is Cafcass, the body that employs social workers who provide independent reports to the courts in child and family proceedings). They do not have the freedom, or the responsibility, to campaign politically within their occupational role. Social workers in different sorts of organisational settings may have greater freedom, or even specific roles, to do so.

There may be circumstances in which social workers could raise matters with a wider audience as part of their professional activity - for example, through membership of a policy review working party, or responding to a government consultation, or undertaking and publishing research (with 
suitable permission and regard for confidentiality). But more vigorous campaigning and direct action are matters which should take place in their own time; and even then, with due regard to the implications for the reputation of the profession and the organisation (the professional integrity dimension, discussed earlier).

What then about the third aspect, if there is something that a social worker considers illegal; or if not illegal, so wrong that they consider they have to take a stand against it directly? In those cases they should be careful to follow their organisation's whistleblowing procedures, as far as possible, and the law. The Public Interest Disclosure Act 1998 (PIDA, as amended by the Enterprise and Regulatory Reform Act 2013) gives a framework for balancing the duties of employees and employers, together with protection for service users and for staff who decide to whistleblow. So, the law does offer some protection for social workers if they make a disclosure which they reasonably believe to be in the public interest. However, it is well known that it can be a very difficult experience to be a whistleblower, provoking a lot of anxiety, and discontent if the person does not think that the right action (or indeed any action) has been taken. Also, despite the legislation, over two-thirds of a sample of 1,000 whistleblowers said that their own situation had got worse as a result of their action (Public Concern at Work and University of Greenwich, 2013).

The law is an essential backstop, but a better outcome would be that organisations build strong cultures in which is acceptable for staff to voice their concerns, so that problems are nipped in the bud. This is reflected in BASW's whistleblowing policy, which emphasises the importance of employers encouraging social workers to speak up, and promoting a positive message about this (BASW, 2014b).

\section{Conclusion}

This chapter has explored some of the conflicts and dilemmas that arise when social work, the law and the courts come into contact. Despite the challenges, the interdisciplinary encounter also gives opportunities, both to uphold better the rights of people who use social work services, and to empower social workers, if it can constructively help them to follow and use the law in the best interests of their service users.

The chapter has given an account of social work values, based on the BASW code of ethics, and explored the themes of judgement and justice. These are key concepts for social work and the law, but there are complexities within each of them, and tensions between the social work and legal approaches. However, there is also potential for the different viewpoints to challenge one another constructively, if this can be done with mutual respect and a genuine will to understand the 
priorities and challenges facing the other professional. This should be combined with a greater awareness of the contradictions and limitations of one's own role, and a readiness to challenge oneself rather than the other person. This sort of reflective and analytic approach, focusing on the implications for practice, is the key to better decision-making and better outcomes for service users.

To conclude, let us revisit the other theme, about the two recent developments in social work thinking, the rediscoveries of radicalism and of relationship-based work. The radical approach gives social work an important vision, so that is not just about passively accepting the existing order and the inequalities and oppression within it (Ife, 2012: 38-39). But it is risky to make overblown claims about challenging oppression and inequality if these cannot legitimately or realistically be achieved (realism is an ethical duty too: Beckett, 2007). However, realistically, much can be: and that takes us back to relationships, and the ways that relationship-based and radical social work can be combined. Good social work starts with a commitment to individuals and families, to treating them with respect and dignity. It starts in the 'small places' (Roosevelt, 1958), the ways that social workers talk to people, and talk about people; the ways they keep people up to date with what is happening, even if 'nothing has happened yet'; the ways they show concern for people (service users and other workers), the little acts of thoughtfulness, generosity and calm determination. It looks at people's needs in the bigger picture, but is still clear-eyed about their interests and the interests of others. Good relationship-based social work is a form of quiet radicalism, and many acts of quiet radicalism can make a powerful force for change. If an organisation can tap into this, encourage it and spread it, then the whole agency could be transformed - and it could go beyond that, to contribute to wider social change. This would be relationship-based radicalism, based on a critical, realistic but still ambitious understanding of social work values. This way of changing practice would not because of courts lecturing social workers (and other professionals) about what they have done wrong. They have been doing this for years, but it does not work because it does not help to spread good practice; if anything it is counter-productive because it destroys morale and drives staff away from these demanding areas of work. Change would have a better chance of succeeding if it starts from social work values. 